\title{
ORIGINAL
}

\section{Changes in condylar and mandibular angles with growth and aging}

\author{
Shigeo Osato and Ken Hiratsuka \\ Department of Oral Anatomy, School of Dentistry at Tokyo, \\ The Nippon Dental University \\ (Chief: Assoc. prof. Shigeo Osato) \\ 1-9-20 Fujimi, Chiyoda-ku, Tokyo, 102, Japan \\ (Accepted for publication: November 18, 1993)
}

Key words : condylar angle/mandibular angle/gonial angle/antegonial angle/mandible

\begin{abstract}
In accordance with Hellman's classification of developmental stages, a total of 278 pieces of the right and left sides from 140 dried mandibles of Asian Indians were classified into four groups- -IIA,IVA, IVC - VA and VIIEJ--and analyzed goniometrically using standard lateral photographs. By doing, this changes of the condylar and mandibular angles with growth and aging were examined.

The condylar angle is defined here as the angle formed by two tangents to the inferior border of the body of the mandible and the posterior border of the ramus, and the mandibular angle as the region of the angular junction where the inferior border of the body of the mandible and the posterior border of the ramus come together and also the angle of the contour formed by that region. Therefore, both angles have to be measured separately:

The condylar angle decreased by $5 \sim 12$ degrees throughout the growth period and increased by 4 degrees due to aging. The mandibular angle was expressed in two angles for the gonial and antegonial angles. The gonial and antegonial angles decreased by 6 degrees during the first half of the growth period. Thereafter, the former increased by 4 degrees only due to aging and the latter did not show any significant variations with growth or aging. It is suggested that the lower and posterior border of the ramus and the backward and inferior border of the body of the mandible contouring the mandibular angle change differently but are closely related with the functional changes in the muscles of mastication due to eruption as well as the loss of permanent teeth.
\end{abstract}

抄録：Hellman's developmental stage（IIA, IVA, IVC・VA および VIIEJ）に準じ，140 個のインド人晒下

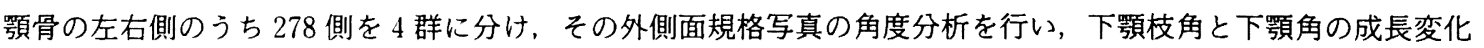
および加齢変化を検索した。

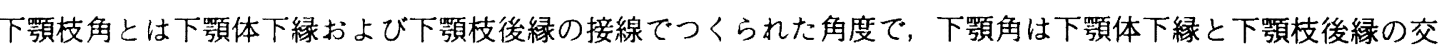
わる角ばった境界部分およびその輪郭の角度を示すため, 両者は別個に測定しなければならない。下顎枝角は成

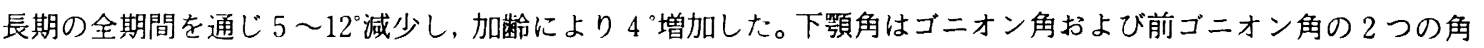
度で表し, 両者は成長期の前半で $6^{\circ}$ 減少した。その後, 前者は加齢でのみ $4^{\circ}$ 増加し, 後者は成長期の後半はもち ろん加齢においても有意な增減は認められなかった。すなわち, 下頡角の輪郭をつくる下顎枝下後縁と下顎体後 下縁は, 永久歯の萌出や跡失による咀嘶筋の機能変化に密接しながら異なった変化を示していた。 


\section{Introduction}

Many reports have been published with regards to changes in the angle of the ramus of the mandible (the condylar angle) and the angle of the mandible in the course of growth from infancy to adulthood. Tsusaki $(1962)^{1)}$, Makita $(1971)^{21}$, Nakaya (1971) ${ }^{3}$, Goss $(1973)^{4)}$, Feneis $(1975)^{5)}$ and Kahle et al. $(1982)^{6}$ explained that the mandibular angle decreases as teething children grow to adolescence and later reach the prime of life with the permanent dentition replacing primary teeth, and starts to increase when they arrive at senescence and lose their teeth.

On the other hand, Brodie $(1940)^{7}$, Iizuka $(1966)^{8}$, Kamijo (1966) ${ }^{91}$ and Dubrul (1980) ${ }^{10)}$ emphasized that an angle in the geometric sense of the mandibular angle changes but the contour of the mandibular angle does not change with growth and aging, resting on the results of analyses of $\mathrm{X}$-ray cephalographs and serial radiographs. Sakurada et al. (1986) ${ }^{11}$ reported that no changes in the condylar angle occur with growth and aging. Kikuchi $(1975)^{12}$ and Kubota and Muramatsu $(1989)^{13)}$ have come up with the results that the condylar angle tends to become obtuse with age but that there were differences in the degree of changes between men and women. Kikkawa (1984) ${ }^{14 /}$ maintained that the protrusion of the mandibular angle is more distinguishable in men than in women. Watanabe (1981) ${ }^{15}$ described that morphological changes are evident and the degree of the mandibular angle becomes notably larger in people of advanced age with edentulous jaws than those the dentulous jaws. More recently, Morita et al. (1992) ${ }^{16}$ reported their findings that the toothless persons have a larger degree of the condylar angle than the persons with 14 or more teeth, and that salient morphological changes have been taken place in the area adjacent to the mandibular angle.

Generally, the terms angle of the ramus of the mandible and angle of the mandible have been used without being defined precisely. The former is almost always used with reference to the angle formed by the body of the mandible and the ramus. The latter is used sometimes to mean the degree of the angle and some-

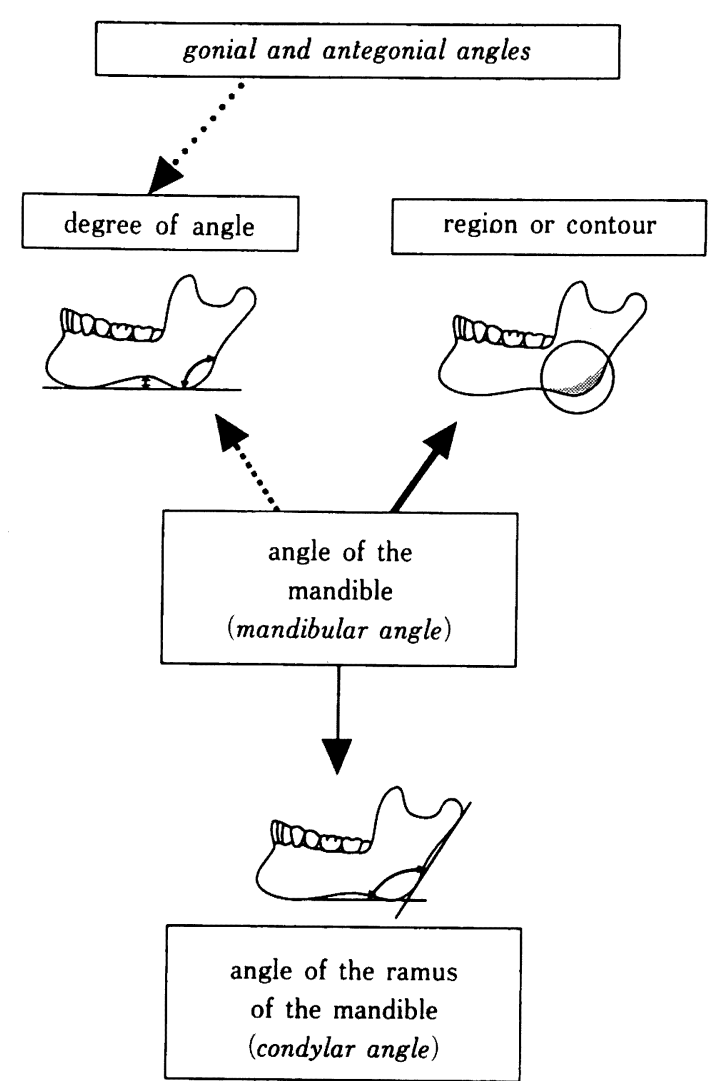

Fig. 1 Does the mandibular angle refer to the angle or the region of the mandible?

The thick line denotes the region of the unclear mandibular angle; the fine line, its angle expressed in the condylar angle; the broken line, the range of the mandibular angle : and the dotted line, mandibular angle which can be also given as the gonial and antegonial angles.

times to denote a certain region of the mandible, or at other times, both. The situation is such that the distinction between both terms has remained confused (Fig. 1). Dubrul ${ }^{10)}$ tried to eliminate this confusion by giving the terms with clear definitions. He first placed a mandible on a table to which a hinged leaf is fastened and gave the term "the condylar angle" (an anthropologic angle) to the inclination of the moval leaf to the table in a position where the leaf touches the posterior border of the mandibular ramus at two points, one near the condyle and the other near the mandibular angle. Meanwhile, the contour of an angu- 
Table 1 Distribution of the mandibular specimens in accordance with Hellman's classification of developmental stages.

\begin{tabular}{ccc}
\hline Group & Mandibles & Right and left sides \\
\hline II A & 61 & 121 \\
IVA & 19 & 38 \\
IVC $\cdot$ VA & 27 & 54 \\
VIIEJ & 33 & 65 \\
\hline total number & 140 & 278 \\
\hline
\end{tabular}

lar region existing on the boundary between the inferior border of the body of the mandible and the posterior border of the mandibular ramus was named "the gonial angle". However, he has not made a reference to the range of the gonial angle.

In a previous study, the authors $(1992)^{17}$ ) defined the scope of the mandibular angle. On this premise, an examination was made on the shape and symmetry of the posterior and inferior borders of the mandibular angle. As a result, it was recognized that various changes in from occur with the transition of the stages from the completion of the primary dentition to the loss of teeth through the eruption of permanent teeth.

In the present study, drawing a clear distinction between the condylar angle and the mandibular angle, we made detailed examinations of the changes of both angles during growth as well as aging.

\section{Materials and Methods}

The materials are the same as those used in a previous report by the authors ${ }^{17}$ ) (Table 1). A total of 278 pieces of the right and left sides from 140 dried mandibles of Asian Indians, their sex unknown, were employed (2 pieces were excluded because both had the broken ramus). The mandibles were classified into four groups in accordance with Hellman's classification of developmental stages- -the completion of deciduous dentition (IIA), the completion of second molar eruption (IVA), third molar eruption to its completion (IVC •VA) and edentulous (VIIEJ) stages. The materials we used in stage VIIEJ include two mandibles, each with only one tooth left.

The method is exactly the same as the previously

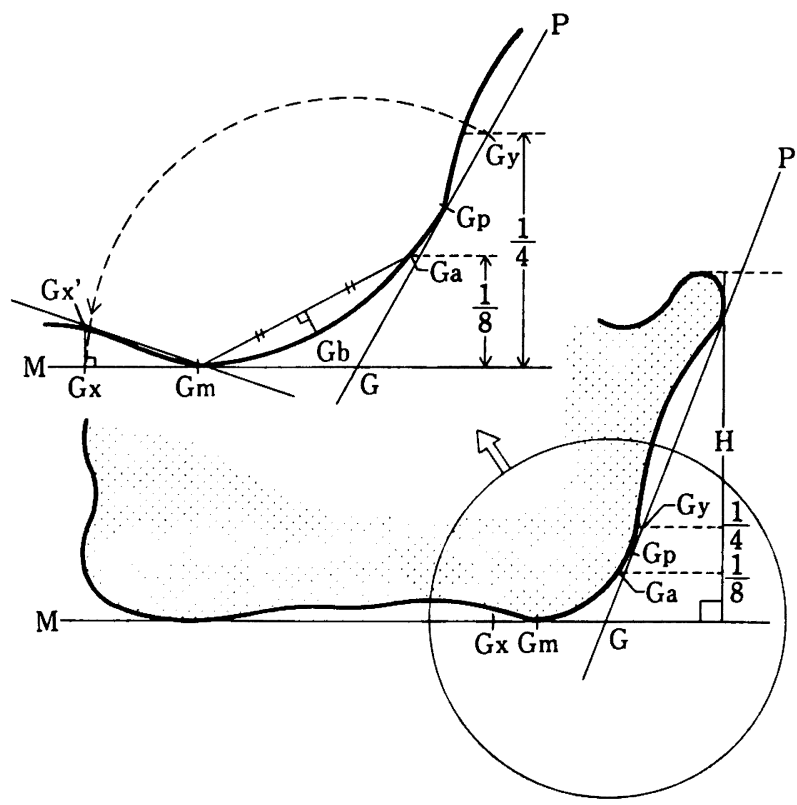

Fig. 2 The region of mandibular angle and measuring points for the angle. The range from $\mathrm{Gy}$ to $\mathrm{Gx}$ in the enlarged diagram shows the region of mandibular angle.

employed standard photography ${ }^{17}$. Figure 2 illustrates the region of the mandibular angle and the measuring points. On the life-size photographs of the lateral aspect of the mandibles, the straight line $\mathrm{M}$ tangent to the inferior border of the body of the mandible and the straight line $\mathrm{P}$ touching the curve of the posterior border of the ramus were drawn, and the point where the two lines intersect was given as G. A point which line $\mathrm{P}$ touches the mandibular angle was given as $\mathrm{Gp}$. Then, line $\mathrm{H}$ which passes through the posterior border of the articular process and which is perpendicular to line $\mathrm{M}$ was drawn, and the point where a horizontal dash line starting at $1 / 8$ of the length of line $\mathrm{H}$ on the inferior side of the mandible meets the posterior border of the ramus was given as $\mathrm{Ga}$. An antegonion ${ }^{18)}$ where the highest point of the concavity of the lower border of the ramus joins the body of the mandible was given as $\mathrm{Gm}$. A straight line was drawn to connect $\mathrm{Ga}$ with point $\mathrm{Gm}$ (antegonion), and the point where the perpendicular line extending from the midpoint of line $\mathrm{Gm}-\mathrm{Ga}$ reaches the posterior border of the angle of the mandible was given as $\mathrm{Gb}$. The point were a horizontal dashed line beginning at $1 / 4$ of 
Table 2 Means, standard deviations and coefficients of variation of the condylar angle, and $t$ tests for variables between groups.

\begin{tabular}{ccccccccc}
\hline Group & MN & S.D. & C.V. & Max. & Min. & Range $\begin{array}{c}\text { difference } \\
\text { between the } \\
\text { stages }\end{array}$ & $t$-test \\
\hline II A & 132 & 5.0 & 3.8 & 143 & 118 & 25 & -5 & $* *$ \\
IVA & 127 & 6.6 & 5.2 & 142 & 115 & 26 & -7 & $* *$ \\
IVC V VA & 120 & 6.5 & 5.4 & 135 & 110 & 25 & 6 & $* *$ \\
VIIEJ & 126 & 6.8 & 5.4 & 138 & 106 & 31 & & $*$ p $<0.01$
\end{tabular}

Table 3 Means, standard deviations and coefficients of variation of the gonial angle, and $t$ tests for variables between groups.

\begin{tabular}{ccccccccc}
\hline Group & MN & S.D. & C.V. & Max. & Min. & Range $\begin{array}{c}\text { difference } \\
\text { between the } \\
\text { stages }\end{array}$ & $t$-test \\
\hline II A & 161 & 8.1 & 5.0 & 180 & 123 & 56 & -6 & $* *$ \\
IVA & 155 & 6.2 & 4.0 & 167 & 141 & 25 & -3 & N.S. \\
IVC - VA & 152 & 8.9 & 5.8 & 172 & 136 & 36 & 4 & $* *$ \\
VIIEJ & 156 & 6.8 & 4.3 & 171 & 137 & 33 & N.S. : no significance, $* * p<0.01$
\end{tabular}

Table 4 Means, standard deviations and coefficients of variation of the antegonial angle. and $t$ tests for variables between groups.

\begin{tabular}{crrrrrrrr}
\hline Group & MN & S.D. & C.V. & Max. & Min. & Range $\begin{array}{c}\text { difference } \\
\text { between the } \\
\text { stages }\end{array}$ & $t$-test \\
\hline II A & 10 & 5.3 & 56.0 & 23 & 0 & 23 & -6 & $* *$ \\
IVA & 4 & 5.2 & 137.4 & 17 & 0 & 17 & 2 & N.S. \\
IVC - VA & 6 & 6.0 & 91.0 & 16 & 0 & 16 & -1 & N.S. \\
VIIEJ & 5 & 6.0 & 109.1 & 22 & 0 & 22 &
\end{tabular}

the inferior side of the length of line $\mathrm{H}$ comes into touch with the tangent line $\mathrm{P}$ to the posterior border of the ramus was given as $\mathrm{Gy}$. The straight line distance from $G$ to $G y$ was sought anteriorly on line $M$ and was given as $\mathrm{Gx}$. A point where a perpendicular line to $\mathrm{Gx}$ on line $\mathrm{M}$ meets the inferior border of the body of the mandible was given as Gx'. The two points $\mathrm{Gx}$ ' and $\mathrm{Gm}$ were connected with a straight line.

The condylar angle and the mandibular angle were measured on the digitizer by the 4-point angular calculation method. The meas values, standard devia- tions and coefficients of variation were summarized for the purpose of statistical analysis. Significant differences in the mean values between Hellman's developmental stages were assessed by the Student's $t$-test and the Welch $t$-test.

\section{Results}

The mean values, standard deviations, and coefficients of variation on the degree of angle of the condylar angle, gonial angle and antegonial angle are shown in Tables 2, 3 and 4. 

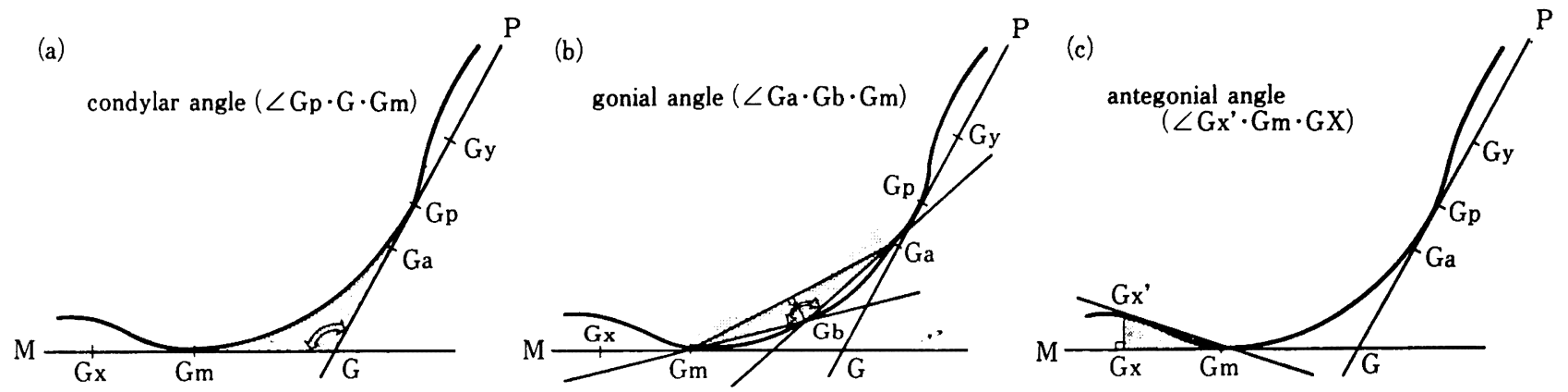

Fig. 3 Measuring points for condylar angle (a), gonial angle (b) and antegonial angle (c), and measuring method.

The method of measurement of the condylar angle is shown in Figure 3 (a). For measuring the condylar angle, the angle formed between the inferior border of the body of the mandible (line $\mathrm{M}$ ) and the posterior border of the ramus (line P) was used. Changes in the degree of the condylar angle are shown in Table 2. The condylar angle in stage IIA was $132 \pm 5$ degrees, which significantly $(\mathrm{p}<0.01)$ decreased by 5 degrees to $127 \pm 6$ in stage IVA. The value further dropped significantly by 7 degrees $(p<0.01)$ to $120 \pm 6$ in the stage of IVC - VA. In stage VIIEJ, however, it showed a significant $(p<0.01)$ increase of 6 degrees from IVC $\cdot \mathrm{VA}$ and reached $126 \pm 6$. The angular range was from 25 to 31 degrees and the coefficients of variation was worked out to be $3.8 \%$ to $5.4 \%$. The condylar angle tended to gradually decline throughout the period of growth of the mandible from stage IIA to stage IVC - VA, and turned upward with aging from stage IVC $\cdot$ VA to stage VIIEJ.

The method of measurement of the gonial angle is shown in Figure 3 (b). To obatin the degree of the gonial angle, the angle formed by the three points- $\mathrm{Ga}$ and $\mathrm{Gb}$ in the posterior border of the mandibular angle and $\mathrm{Gm}$ observed in the lowest border of the mandibular angle $(\angle \mathrm{Ga} \cdot \mathrm{Gb} \cdot \mathrm{Gm})$--was taken. Changes in the degree of angle of the gonial angle are shown in Table 3.

The gonial angle in stage IIA was $161 \pm 8$. In stage IVA, the value dropped significantly $(\mathrm{p}<0.01)$ by 6 degrees to $155 \pm 6$. The value continued to decrease to $152 \pm 8$ in stage IVC $\cdot V A$. But the decrease of 3 degrees from stage IVA is not significant. The decreasing trend turned upward in stage VIIEJ to $156 \pm 6$, a significant $(p<0.01)$ rise of 4 degrees from stage
IVC - VA. The angular range was from 25 to 56 degrees, exceeding the range of the condylar angles. The coefficients of variation came up to $4.0 \sim 5.8 \%$, approximating to that of the condylar angle. The degree of the gonial angle decreased during the growth period from stage IIA to stage IVC $\cdot \mathrm{VA}$, and increased from stage IVC - VA to stage VIIEJ due to aging. Such variations in the gonial angle were almost parallel with those in the condylar angle.

The method of measuring the antegonial angle is shown in Figure 3 (c). The inferior border of the body of the mandible was not necessarily flat and varied in shape depending upon the development of the antegonial notch. In the present study, the measurement of the antegonial angle was taken at $\angle \mathrm{Gx}$ ' $\mathrm{Gm} \cdot \mathrm{Gx}$, formed by $\mathrm{Gx}$ ' and $\mathrm{Gm}$ on the inferior border of the mandibular angle and $\mathrm{Gx}$ on line $\mathrm{M}$.

Table 4 shows the angular changes of the antegonial angle. The antegonial angle measured $10 \pm$ 5 in stage IIA of the mandibles and $4 \pm 5$ in stage IVA, showing a significant $(p<0.01)$ decrease of 6 degrees. The angle increased by 2 degrees to $6 \pm 6$ in stage IVC $\cdot V A$, however, there is no significant difference. An antegonial angle in stage IVC.VA came to decrease again by an insignificant 1 degree to $5 \pm 6$ in stage VIIEJ. The angular range of 16 to 23 was smaller than to the range of the condylar angle. The coefficients of variation varied as wide as 56.0 $137.4 \%$. The degree of the antegonial angle decreased only from stage IIA to stage IVA which correspond to the first half of the period of growth. The angle during the latter half of the period of growth, from stage IVA to stage IVC - VA and further stages from IVC - VA to VIIEJ, there were no salient angular changes due to 


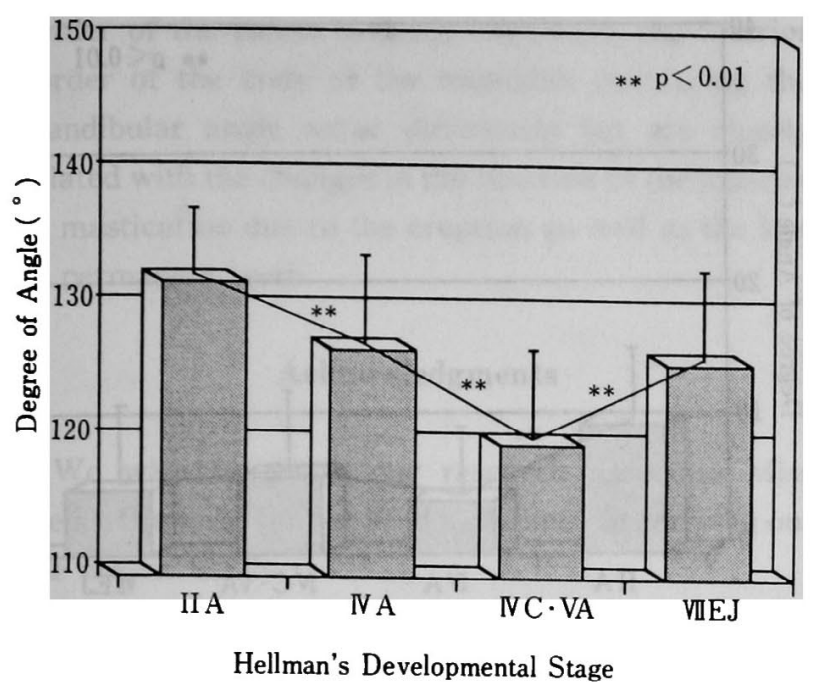

Fig. 4 Changes in the condylar angle with growth and aging.

growth and aging.

\section{Discussion}

The degree of the mandibular angle, if measured by a mandibulometer ${ }^{19)}$ as described in a Martin-Saller textbook or a stativgoniometer ${ }^{20)}$ in Suzuki's "Anthropometry", can be expressed in an angle formed by two straight lines, despite the fact that the posterior border of the mandibular ramus and the inferior border of the body of the mandible are irregularly curved. The shortcomings of this method are that the measurements are affected considerably by the growth of the condylar cartilage and the morphological changes in the posterior border of the articular condyle due to the loss of premolars and molars and disorder of the masticatory function. Furthermore, the shape of the posterior border of the mandibular angle is rounded and the depression of the antegonial notch in the inferior border of the mandibular angle is neglected. It cannot be said that the results obtained by the conventional report fully reflect the appropriate shape of the mandibular angle.

To overcome the above-mentioned shortcomings, the present authors ${ }^{17)}$ limited the range of the mandibular angle to the area $G y-G$ in $1 / 4$ of the height of the ramus and the area $G x-G$ on line $M$ tangent to the inferior border of the body of the mandible. We stud- ied new methods by drawing numerous lines on the lateral view of the mandibular angle. Our study found that it is difficult to express the range of the mandibular angle $\angle \mathrm{Gy} \cdot \mathrm{G} \cdot \mathrm{Gx}$ in a single angle and the angle of the contour of the mandibular angle by using Gy. From this fact, the mandibular angle was expressed in two angles for the posterior border and the inferior border. The former was obtained by measuring $\angle \mathrm{Ga} \cdot \mathrm{Gb} \cdot \mathrm{Gm}$ with the region of the gonial angle, and the latter was worked out by measuring the antegonial angle $\angle \mathrm{Gx} \cdot \mathrm{Gm} \cdot \mathrm{Gx}$ (Fig. 1).

There are two observations available in regards to the changes in the mandibular angles due to the growth of the mandible and due to aging. Iizuka ${ }^{8}$, after X-ray cephalometric analysis, reported that the angle was 130 degrees in stage IIA and 131 degrees in stage IVA and that no further change was observed. On the other hand, without taking account of the effect of the posterior border of the condyle and the inferior border of the body of the mandible, Tsusaki ${ }^{11}$ and Kahle et al. ${ }^{6}$ published the results of the measurement of the condylar angle as those of the mandibular angle. They remarked that the angle was changed with age- -150 degrees for the neonates and infants, $120 \sim 130$ degrees for the adults and 140 degrees for the aged.

Kubota and Muramatsu ${ }^{13)}$ took radiographs of the profiles of median sectioned mandibles from many cadavers, measured in a way similar to cephalometry, and explained that age-wise differences are not significant both in dentulous and edentulous jaws, but that a difference of 6 degrees was noted between 125 degrees in dentulous jaws and 131 degrees in edentulous jaws in the prime of life. Although their radiographic procedures were different from ours, the difference of 6 degrees coincided with what we found in the current study.

As shown in Figure 4, the changes in the condylar angle in our study tapered off. The 132 degrees of angle shown in stage IIA was gradually reduced by 5 $\sim 12$ degrees as the stage advanced from IVA to IVC. VA. This is considered due to the development of the mandibular angle and the articular condyle, as if drawing an arc posterosuperiorly from the anterosuperior region of the mandibular angle, in adaptation 


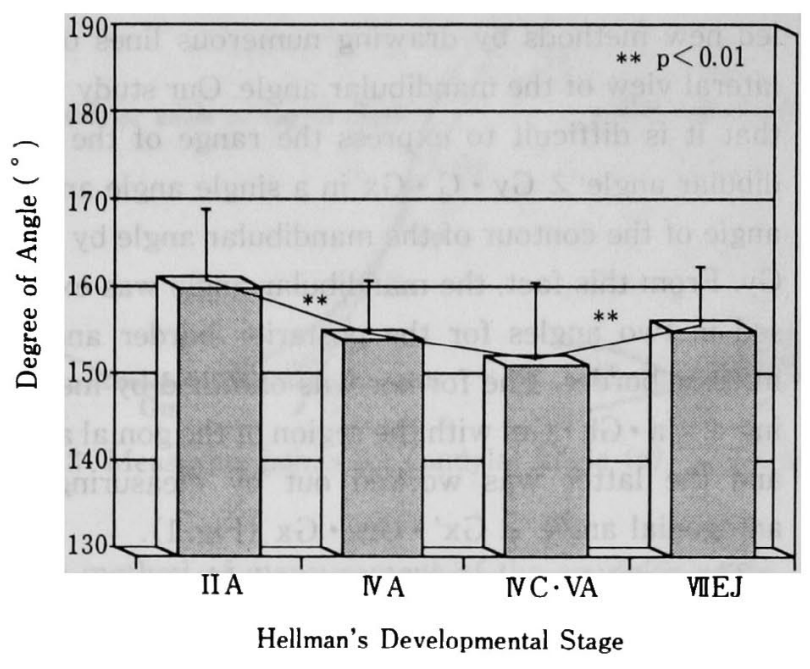

Fig. 5 Changes in the gonial angle with growth and aging.

to the development of the mandible and the stress of the muscles of the mastication attached to it with growth of physique ${ }^{21.22)}$, which results in the decrease in the condylar angle (23 26). $^{2}$.

Likewise, the changes in the growth period of the gonial angle become smaller (Fig. 5). The angle shown in stage IIA was 161 degrees, and in stage IVA it decreased significantly by 6 degrees. Then, angular changes were not significantly observed in stage IVC - VA. This suggests that before the eruption of the second molar is complete, the posterior border of the mandibular angle, which undergoes a morphological change to adapt to the development of the muscles of mastication and their muscular function, is not subject to the myofunctional strength with the eruption of wisdom teeth. After stage IVC VA, however, the condylar angle expanded by 6 degrees and the gonial angle increased by 4 degrees, with loss of all teeth (Fig. 5). This can be attributed to the hypofunction of the muscles of mastication due to the loss of the vertical dimension, which results in the decrease in myodynamics and a change in the shape of the area to which the muscles are attached. The angular changes in the gonial angle from $\mathrm{Ga}$ to $\mathrm{Gm}$ could be observed clearly even if measurements are taken without regard to the effects of the loss of teeth on the posterior border of the condyle.

The changes in the angle between the inferior bor-

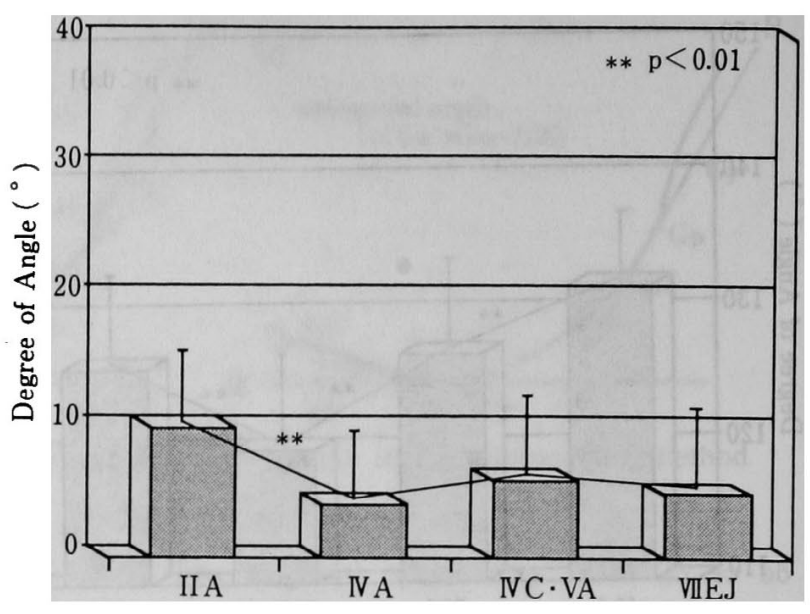

Hellman's Developmental Stage

Fig. 6 Changes in the antegonial angle with growth and aging.

der of the mandibular angle and the horizontal plane are shown in Figure 6 . The angle taken in stage IIA was 10 degrees, which dropped to 6 degrees in stage IVA but remained almost the same in stage IVC - VA. It suggested that the $\mathrm{drift}^{27)}$ of the location to a posterosuperior region near the mandibular angle and the remodeling of bone in the antegonial notch scarcely occurred due to the eruption of wisdom teeth. Even after all the teeth are lost, our study showed that the antegonial notch, once formed, does not change notably. The $\mathrm{Gx}^{\prime}-\mathrm{Gm}$ in the inferior border of the mandibular angle rarely came into contact with the horizontal plane in either stage. It separated from the plane almost all of the mandibles used in our study. This observation differs from that of Watanabe ${ }^{15)}$ who asserted that an area adjacent to the mandibular angle was absorbed with aging and was straight in edentulous jaws, but agrees with Ichijyo's observation $^{28)}$ that there was a shallow depression. The bone remodeling in the antegonial notch observed posterior to the inferior border of the body of the mandible was remarkable only during the first half of the growth period.

From all the results mentioned above, it can be said that the condylar angle changes notably with the replacement of teeth, the eruption of additional teeth and complete loss of teeth. It was also suggested that morphological changes in the lower and posterior 
border of the ramus and the backward and inferior border of the body of the mandible contouring the mandibular angle occur differently but are closely related with the changes in the function of the muscles of mastication due to the eruption as well as the loss of permanent teeth.

\section{Acknowledgments}

We wish to thank our research associate Miss Keiko Ohmura, for her kind assistance in carrying out the present study.

\section{Refferences}

1) Tsusaki, T. : A Newly Edited Oral Anatomy, 1 st edn., pp. 10 16, Nagasue-bookstore, Tokyo, 1975 (in Japanese).

2) Makita, Y.: On the morphological changes in the skulls of deciduous, permanent and edentulous jaws. Nihon Univ. Dent. J. $67: 892 \sim 899,1980$ (in Japanese).

3) Nakaya, J. : Anatomical studies of the mandible of human children. Shikwa-Gakuho $71: 239 \sim 251$, 1971 (in Japanese).

4) Goss, C. H. : Gray's Anatomy of the Human Body, 29 th edn., pp. 152 158, Lea \& Febiger, Philadelphia, 1973.

5) Feneis, H. : Anatomisches Bildwöuterbuchder Internationalen NomenKlatur. Yamada, A. Editor in japanese : Illustrated Anatomical Dictionary. 1 st edn., pp. 28 29, Igaku-shoin, Tokyo, 1975 (in Japanese).

6) Kahle, W., Leonhardt, H. and Platzer, W. : Taschennatlas der Anatomie. Ochi, J. Editor in Japanese: Atlas of Anatomy. 1 st edn., pp. 151, Bunkou-do, Tokyo, 1982 (in Japanese).

7) Brodie, A. G. : Some recent observations on the growth of mandible. Angle Orthodont. 10:63 77, 1940.

8) Iizuka, T. : Toubu $X$-sen kikakushyashin niyoru nihonjin shyouni no kao no seichyo ni kansuru kenkyuu. J. Stomatol. Soc., Jpn. $25: 260 \sim 272$, 1958 (in Japanese).

9) Kamijo, Y.: Oral Anatomy, 1 Osteology, 2 nd edn., pp. 309 310, pp. 348, Anatohmu company, Tokyo, 1966 (in Japanese).

10) Dubrul, E. L. : Sicher's Oral Anatomy, 7 th edn., pp. 124 130, The C. V. Mosby company, St. Louis, 1980.

11) Sakurada, M. and Furuta, Y. : A study of the developmental changes of Indian mandibles Part 2. The Relation between weigt and breadth, and weight and angle. Shigaku (Odontology) $73: 1433$ $\sim 1466,1986$ (in Japanese).

12) Kikuchi, M. : Senile changes of modern Japanese skull. Niigata Med. J. 90:86〜96, 1976 (in Japanese).

13) Kubota, K. and Muramatsu, H. : Comparison of chronological changes of various angle measurements taken from lateral view of adult Japanese mandible. Nihon Univ. Dent. J. 63 : 683 692, 1989 (in Japanese).

14) Kikkawa, F. : Systematic Human Anatomy, 1 st edn., pp. 123 124, Nanzan-do, Tokyo, 1984 (in Japanese).

15) Watanabe, I. : Gerodontology, 1 st edn, pp. 63 $\sim 73$, Ishiyaku publishers, Inc., Tokyo, 1981 (in Japanese).

16) Morita, T., Kageyama, I., Fukushima, O., Takeuchi, S., Kato, S. and Yamashita, H. : The transformation of the shape of the mandible with total teeth loss. Acta Anat. Nippon $67: 508,1992$.

17) Hiratsuka, K., Osato, S. and Takeda, N. : The aspect of the gonial angle I. Morphological changes in the lateral aspect of the gonial angles. Shigaku (Odontology) 80:10 20, 1992 (in Japanese).

18) Enlow, D. H. : Facial Growth, 3 rd edn., pp. 391 $\sim 395$, W. B. Saunders company, Philadelphia, 1990.

19) Saller, K.: Lehrbuch der Anthologie in Systematischer Darstelling, Band I, 3 rd edn., pp. 293, Gustav Fisher Verlag, Stuttgart. 1957.

20) Suzuki, H. : Anthropometry, 1 st edn., pp. 1 106, Ningen to Gijutsusha, Tokyo, 1973 (in Japanese).

21) Ricketts, R. M. : The value of cephalometrics and computerized technology. Angle Ortho. 42:179 $\sim 199,1972$.

22) Ricketts, R. M. : A principle of arcial growth of the mandible. Angle Ortho. 42:368 385, 1972.

23) Masuda, T. : Kagakukotsu no kouzo narabini rikigakuteki-kenkyuu, 2 Nijigen koudansei-jikken niyoru kagakukotsu no rikigakuteki-kenkyuu. Koukuu-kaibou-kenkyuu $17: 526 \sim 537$, 1960 (in Japanese).

24) Masuda, T.: Kagakukotsu no kouzo narabini 
rikigakuteki-kenkyuu, 3 Nijigen koudansei-jikken niyoru kagakukotsu no rikigakuteki-kenkyuu. Koukuu-kaibou-kenkyuu $17: 538 \sim 541$, 1960 (in Japanese).

25) Yamada, K. : A histological study on the migration mechanism of the attachment of the deep layer of the masseter muscle to the rat mandible during growth. Jpn. J. Oral Biol. $27: 254 \sim 271$, 1985.

26) Yamada, K., Hanada, K., Ozawa, E. and Morita, S. : A histological study on changes in the attachment of the deep layer of the masseter muscle to the rat mandible during bite raising. Norimatsu, H. Editor in Japanese : Quantitative Analysis of Bone. 1 st edn., pp. $169 \sim 177$, Nishimura bookstore, Niigata, 1986.

27) Enlow, D. H. : Miura, F. Editor in Japanese: Handbook of Facial Growth, 1 st edn., pp.1 47, 76 146, 381 387, Ishiyaku publishers, Inc., Tokyo, 1980.

28) Ichijo, S. : The practice of complete denture prosthodontics (7)-A life of mandible (3)-. The Nippon Dental Review $490:$ 143 159, 1983. 